\title{
Tratamento da mastite clínica bovina com associação de cefalexina, neomicina e prednisolona: resultados preliminares
}

Hélio Langoni[a]",Felipe Morales Dalanezi[a], Sâmea Fernandes Joaquim ${ }^{[a]}$, Benedito Donizete Menozzi ${ }^{[a]}$, Bruno Sivieri de Lima ${ }^{[b]}$, Luc Durel[c], Gustave Decuadro-Hansen ${ }^{[\mathrm{d}]}$

\footnotetext{
[a] Departamento de Higiene Veterinária e Saúde Pública, Faculdade de Medicina Veterinária e Zootecnia, Universidade Estadual Paulista (UNESP,) Botucatu, SP, Brasil

${ }^{[b]}$ Virbac do Brasil, São Paulo, SP, Brasil

[c] Virbac França, Carros, Alpes-Maritimes, França

[d] Virbac América Latina, Buenos Aires, Argentina
}

*Autor correspondente

e-mail: hlangoni@fmvz.unesp.br

\section{Resumo}

A mastite é um processo infeccioso da glândula mamária, que impacta negativamente a cadeia produtiva do leite tanto a nível de produtor quanto da indústria de laticínios. 0 seu tratamento deve ser iniciado imediatamente após o diagnóstico pelas alterações do leite, nos casos clínicos da infecção. Formulações de amplo espectro são importantes como opções para os protocolos de tratamento estabelecidos nas propriedades. Medidas de controle incluindo o tratamento são imprescindíveis para minimizar o problema. Avaliou-se a ação do tratamento de casos de mastites clínicas agudas com o medicamento Rilexine 200 NP intramamário (Virbac): cefalexina, neomicina e prednisolona, a cada 12 horas, durante dois dias - quatro aplicações. Amostras de leite de casos clínicos de mastite foram obtidas no início do desenvolvimento do processo infeccioso pelo exame da caneca de fundo negro. Após desinfecção dos tetos com álcool iodado a 0,5\%, desprezando-se os primeiros jatos de leite, foram coletadas as amostras em frascos estéreis, por pessoal previamente treinado, e congeladas pelo período de 7 dias, sendo encaminhadas para o laboratório onde foram cultivadas em meio de ágar sangue bovino 8\% e ágar McConckey. Imediatamente após a coleta, iniciava-se o tratamento de acordo com o protocolo, com novas coletas de leite 7, 14 e 21 dias após o término do tratamento para estimativa de cura microbiológica. Foram tratados casos de mastite causada por Staphylococcus spp. [Staphylococcus coagulase negativa (SCN) e Staphylococcus aureus], Streptococcus spp. (Streptococcus agalactiae, Streptococcus uberis e Streptococcus dysgalactiae), Corynebacterium bovis e Escherichia coli. Considerando-se todos os casos tratados, independente do patógeno envolvido, tem-se 
que de 73 casos tratados, observou-se a cura microbiológica em 60 animais (taxa de cura de 82,29\%). As porcentagens de cura para os patógenos foram: S.aureus 55,6\% (5/9), SCN 83,3\% (10/12), Streptococcus spp. 80,0\% (24/30), E. coli 94,1\% (16/17) e C. bovis 100\% (5/5). Apesar da diferença do número de patógenos envolvidos nos tratamentos, por tratar-se de resultados preliminares, tem-se uma melhor ação para SCN $(83,3 \%)$ e Streptococcus spp. (80,0\%). Levando-se em consideração os resultados obtidos neste estudo, conclui-se que o uso combinado de cefalexina, neomicina e prednisolona em casos de mastite clínica aguda bovina resulta em alta taxa de cura clínica e bacteriológica. 